\title{
Medication use by Team South Africa during the XXVIIIth Olympiad: A model for quantity estimation for multi-coded team events
}

\author{
Wayne E Derman (MB ChB, BSc (Med)(Hons), PhD, FACSM, FFIMS) \\ UCT/MRC Research Unit for Exercise Science and Sports Medicine, Sports Science Institute of South Africa, Cape Town
}

\begin{abstract}
Objective. This descriptive study was undertaken to report the medications used by the athletes and officials of Team South Africa at the 2004 Olympic Games and to provide a model for the estimation of quantities to be used for planning support to future events.
\end{abstract}

Setting. South African medical facility, 2004 Olympic Games, Athens, Greece.

Methods. The names of the medications, including the dosage and quantity of medications dispensed, were recorded in the pharmacy stock control book at the South African medical facility, 2004 Olympic Games, Athens, Greece. Retrospective review of patient files and medical encounter forms was also undertaken to check against the pharmacy stock control book to ensure complete data capture of dispensed medications.

Main outcome measures. Quantities of medications consumed during the observation period. The units of medication consumed per travelling team member were calculated by dividing the number of units (tablets, capsules, tubes, inhalers, bottles and ampoules) used during the trip by the total number of travelling team members.

Results. Complete records of medications included in the travelling pharmacy are described. Quantities of medications included ranged from single units to 2250 units and percentage use of various medications varied from $0 \%$ to $100 \%$ of stocks. Units per team member ranged from 0 to 9.43 . Medications were consumed from all categories of agents. The most utilised agents included

\section{CORRESPONDENCE:}

Professor Wayne Derman

UCT/MRC Research Unit for Exercise Science and Sports Medicine

Sport Science Institute of South Africa

Boundary Rd

Newlands 7700

Cape Town, South Africa

Tel: 27-21-659-5644

Fax: 27-21-659-5633

E-mail: wayne.derman@uct.ac.za the analgesics, musculoskeletal and non-steroidal anti-inflammatory agents as well as certain vitamin and mineral supplements.

Conclusions. This study describes the consumption of pharmacological agents by the athletes and officials of Team South Africa during the Athens 2004 Olympic Games. It also provides a model to assist with the estimation of quantities of medications to be included in the travelling pharmacy for future international multicoded sports events.

\section{Introduction}

Participation in multi-coded sports events often involves travel to international destinations. In South Africa, multi-coded teams are selected on a number of occasions during the year to participate in local competitions (SA Games, SA Student Games); continental zonal competitions (Zone 6 Games); continental competitions (All Africa Games); and intercontinental competitions (Commonwealth Games, World Student Games and Olympic Games).

A significant part of the preparations and tasks of a team physician includes the decisions regarding the medical supply kit. ${ }^{2,12}$ Complete preparation requires the choice of medications in sufficient quantity to cater for most medical problems that are encountered in multi-coded team events. ${ }^{4,5,8}$ While the medical support structures of the host country might be able to supply an adequate quantity and variety of medications through a polyclinic pharmacy, it is often the case that the foreign country is unable to do so, or the labels and drug information might be presented in a foreign language. ${ }^{10,11}$ Furthermore, issues with respect to quality control and possible contamination of substances require the composition of a medical kit of sufficient variety and quantity to allow for the management of the medical conditions encountered during travel to foreign destinations.

Thus the choice of which compounds to include in such kit and at what quantities is often a perplexing challenge for the team physician. The aim of this report is to document the various medications and quantity usage of medications during the Olympic Games in Athens 2004. A model is also presented to calculate the anticipated quantities of medications in future events.

\section{Methods}

Data were collected over 30 days, starting when the team arrived in Athens (1 Sept) until the end of the Olympic Games (30 Sept). All 
medications dispensed, over this period to both athletes and officials were recorded by the attending team physicians in the pharmacy stock control book in the medical room of Team SA. The names of the medications, including the dosage and quantity of medications dispensed, were recorded. Retrospective review of patient files and medical encounter forms was also undertaken to check against the pharmacy stock control book to ensure complete data capture of dispensed medications.

The pharmacological constituents of each medication as well as quantities of medications were forwarded to the medical authorities of the host country for importation clearance prior to leaving South Africa. Following completion of the travel, the above data were added to the database to allow the calculation of the percentage of medication stocks used. The units of medications per travelling team member were calculated by dividing the number of units (tablets, capsules, tubes, inhalers, bottles and ampoules) used during the trip by the total number of travelling team members.

\section{Results}

A total of 159 team members travelled to Athens. The team comprised 107 athletes from 12 sports codes and 52 officials. Athletes were defined as the members of the team engaged in competition and officials were defined as team or athlete coaches, team managers, team technical staff, administration officials, medical staff and National Olympic Committee members.

The medical consultations conducted during the 30-day period are described elsewhere in this publication. ${ }^{5}$ The medications, active ingredients, dosage, and quantities of medications used, are shown in Tables I - IV.

Table I lists the pharmacological agents in the categories of neurological preparations, local anaesthetics, analgesics, musculoskeletal agents, autacoids and corticoids, and cardiovascular agents. Table II lists the pharmacological agents of the respiratory system, ear nose and throat drugs and drugs to manage gastrointestinal complaints. Dermatological and ophthalmic preparations, antimicrobials and drugs to treat urogenital complaints are listed in Table III while Table IV lists vitamin, mineral and electrolyte supplements as well as the drugs used for emergency management.

Quantities of medications ranged from single units to 2250 units and percentage use of various medications varied from $0 \%$ to $100 \%$ of stocks. Units per team member ranged from 0 to 9.43 . Medications were consumed from all categories of agents yet certain agents were used to a far greater extent. These agents included the analgesics, musculoskeletal and non-steroidal anti-inflammatory agents as well as certain vitamin and mineral supplements.

\section{Discussion}

The 'travelling pharmacy' of Team South Africa consists of two large metal crates-on-wheels to facilitate being pushed during travel as their weight is in excess of $150 \mathrm{~kg}$ per container. This pharmacy is passed from one medical team to another and is used for most of South Africa's multi-coded team events, including student games, African Zonal Games, All Africa, Commonwealth and Olympic/Paralympic Games. The pharmacy stock is checked prior to each trip for expired agents, and remaining quantities of stock from the previous trip are determined.

Of the many responsibilities of a team physician, the decision of which agents to take to an international destination to successfully manage a team of athletes and officials is perhaps one of the more difficult. ${ }^{1}$ The team physicians have to be prepared to manage any medical complaint that might occur in a team of $100-500$ athletes and officials. Medical complaints in a squad of that size can be both diverse in nature and numerous. For example, it is not uncommon on a single trip to be expected to manage a minor outbreak of gastroenteritis, renal stones, myocardial infarction, diabetes complications, acute psychosis and a variety of musculoskeletal injuries.

It is prudent to select a sufficient variety of agents and in sufficient quantities to be independent of the services provided by the host country. While host country services can be excellent and 'stateof-the-art', they can vary greatly depending on their geographical location and the choice of available medications as selected by the local pharmacist. ${ }^{10}$ Furthermore, certain medications might simply not be available in the host country or stock might be limited, or there might be delays in accessing host polyclinic services, leading to a delay in patient management. In some countries, the constituents of certain common medications can vary and contamination of agents can also occur. Thus a comprehensive, sufficiently stocked medical supply kit is important.

Factors influencing the choice of which agents to include in the travelling pharmacy include: personal preference of the team physician(s); unused unexpired medications from the previous trip; the country of destination and the anticipated medical problems (e.g. travelling to an area where malaria is endemic would require certain choices and quantities of agents); the nature of the team and individual sports included in the programme (e.g. athletes involved in contact sports could require increased quantities of analgesics and anti-inflammatory agents); ${ }^{7}$ the legislation of the country of destination (e.g. stopayne is not permitted for importation into Australia); and sponsorship of products from various pharmaceutical companies.

Yet, estimation of quantities of these required agents is often difficult. The above list of medications provides the reader with the details of compounds included in the travelling pharmacy, the quantity taken, usage thereof and the number of units per team member consumed during the time of the Athens 2004 Olympic Games. This latter number (which appears in column number 7) in Tables I - IV is particularly useful as it can be multiplied by the total number of persons in any future travelling party, and provides the physician with an estimated quantity of required medication based on a 30-day period. If the travel period is shorter (e.g. 2 weeks, the amount can be halved or if the trip is 6 weeks the number can be multiplied by 1.5). Clearly, this factor provides a guide only and is likely to vary, based on the above-mentioned variables.

Usage of the analgesics and non-steroidal anti-inflammatory agents warrants special mention. While choice of a certain preparation over another would depend on factors including time to onset of action, desired route of administration and preference of both physician and athlete, it is of interest to note the use of the total number of units of all anti-inflammatory and analgesic tablets (and patches). The total number of units per team member for both these agents is 2.2. Therefore for a team size of 300 members the total 


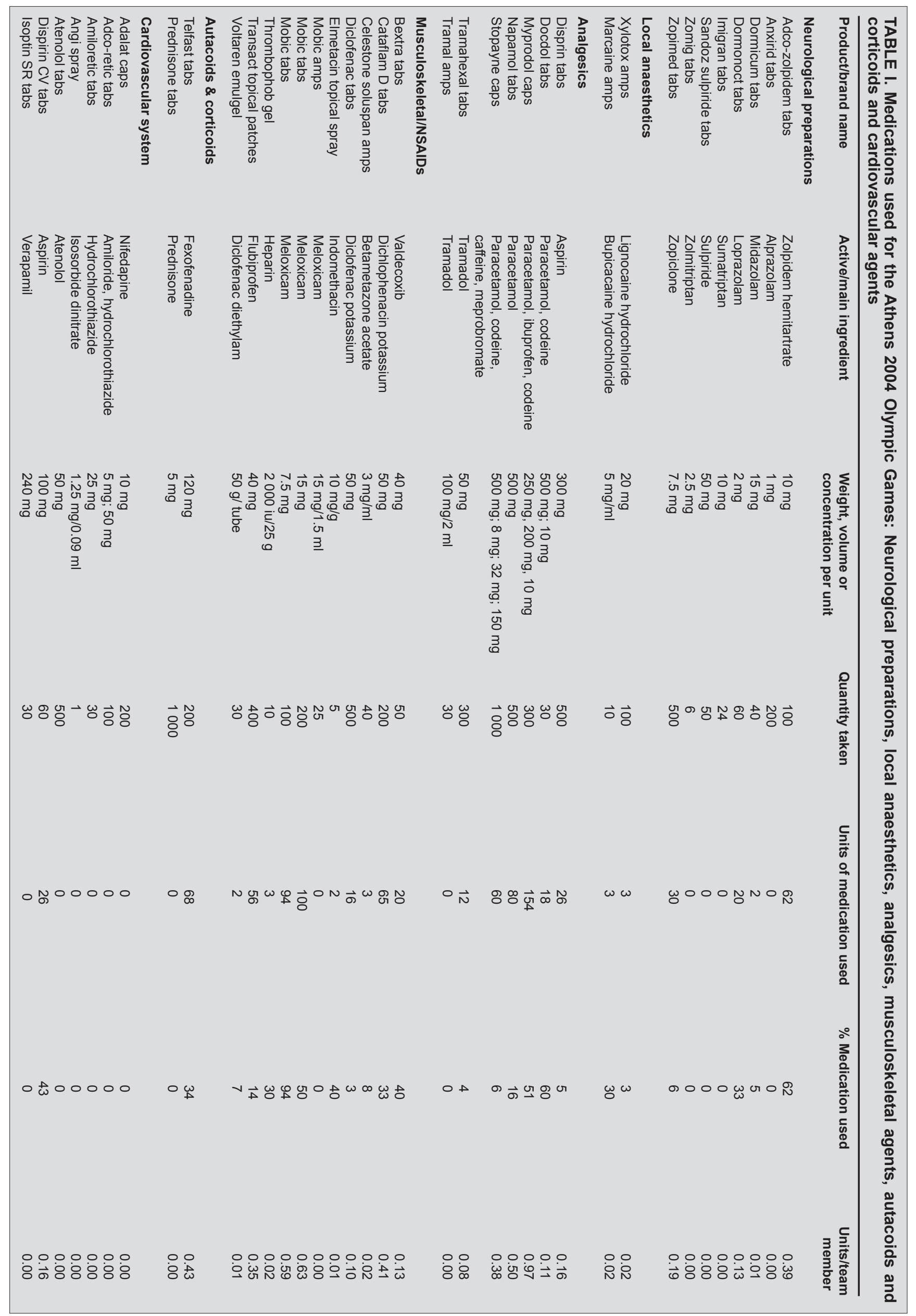




\section{商}

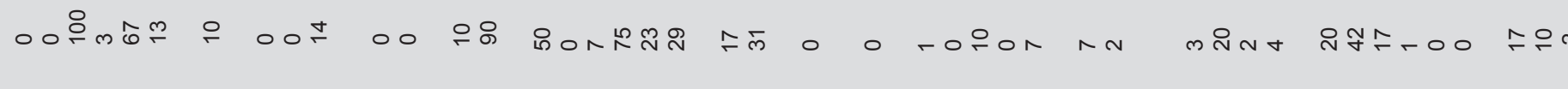

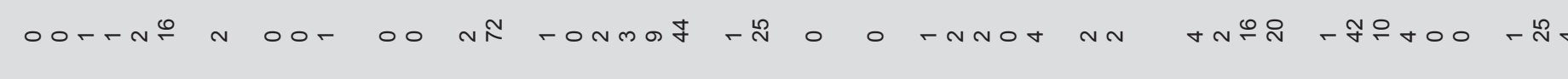

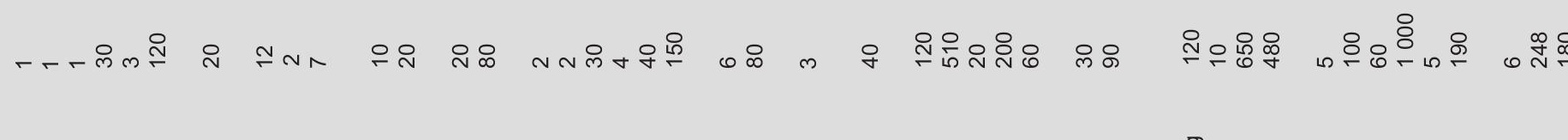

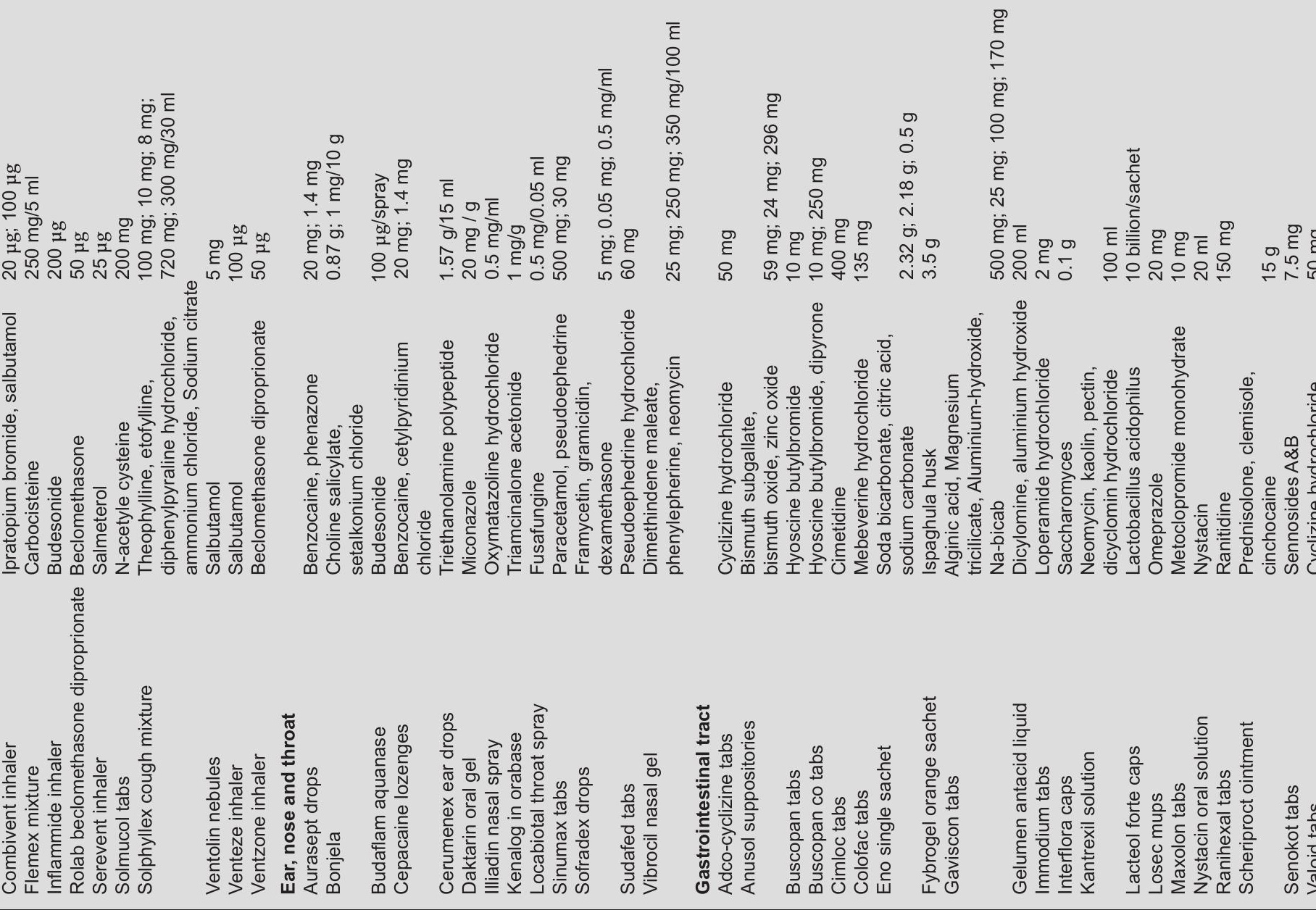




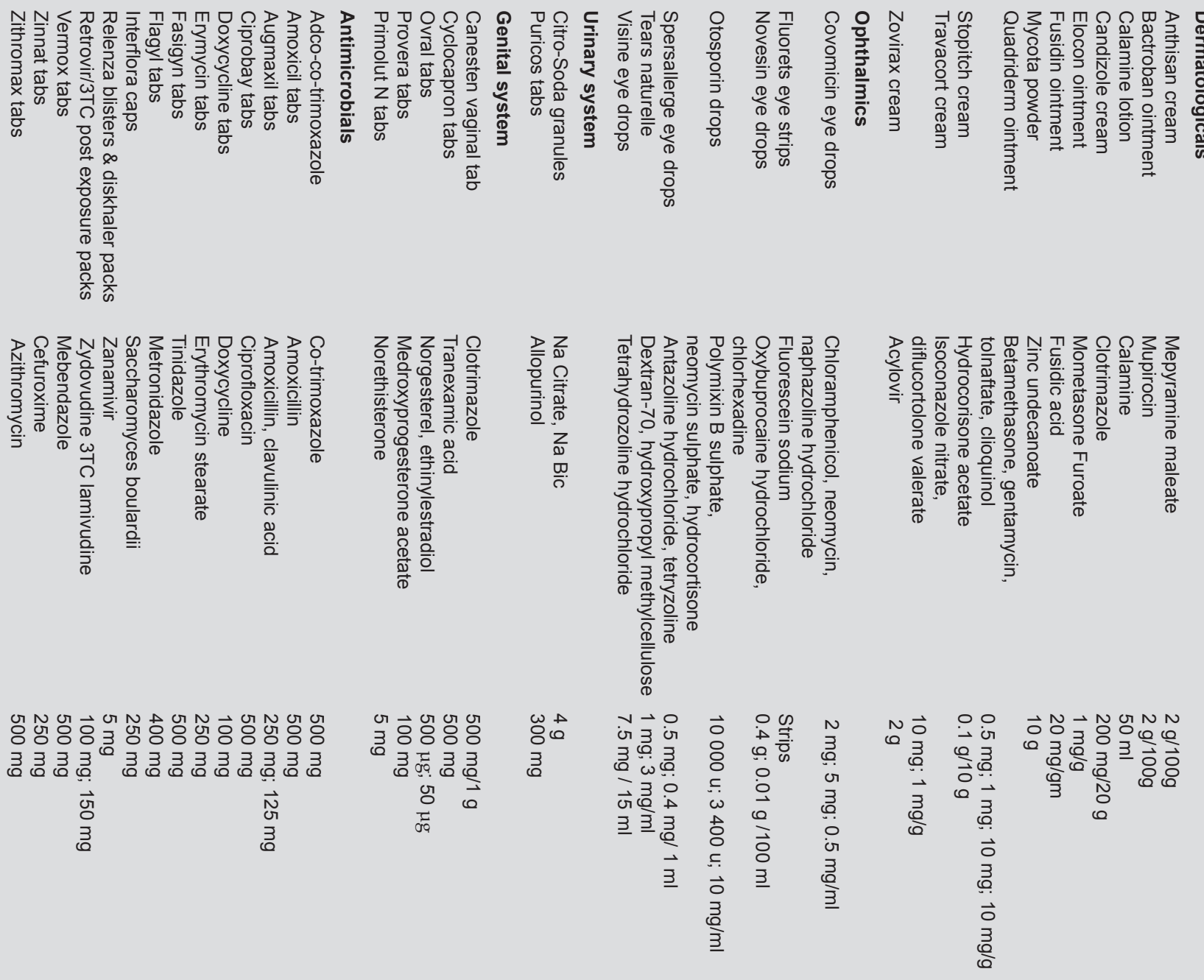

○ी

n.

W NOOO 


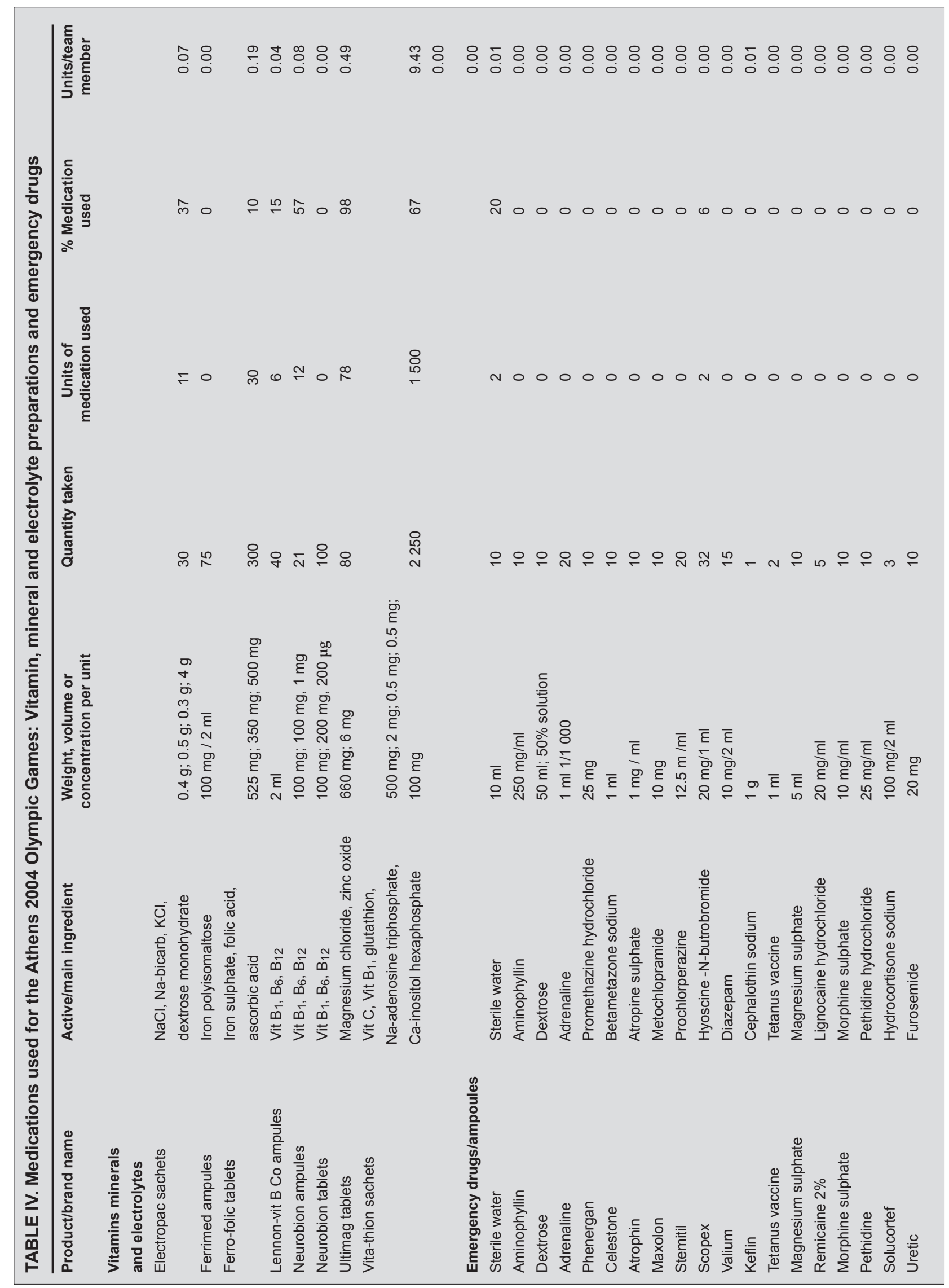


number of doses of these agents would be 660 tablets/capsules/ patches of non-steroidal anti-inflammatory agents and 660 tablets capsules of analgesic compounds based on a 30-day trip. This figure does not include injectable agents, the usage of which is indicated in Table I. The true consumption of non-steroidal anti-inflammatory agents during this event was however somewhat underestimated in this calculation, as it does not take into account flurbiprofen patches and other transdermal anti-inflammatories dispensed by the physiotherapists, or self-medication by the athletes using their own medication supplies. ${ }^{14}$ It is thus apparent that double or tripledosing of these agents regularly occurs and as these agents are not without side-effects, ${ }^{3,6,9}$ it is important that good communication exists between the physicians and physiotherapist with respect to dispensing of non-steroidal anti-inflammatory agents, and that the athletes are educated with respect to judicious use of these medications. ${ }^{13}$ It is therefore suggested that dispensing of all medications is conducted by the team physicians only. Furthermore, dispensing of small quantities of these agents with frequent reevaluation of the patient is preferable to dispensing larger quantities in original packaging. Indeed, this recommendation extends to the use of all medicinal compounds listed and not only the analgesics and anti-inflammatory agents.

In conclusion, this study describes the consumption of pharmacological agents by the athletes and officials of Team South Africa during the Athens 2004 Olympic Games. It also provides a model to be used as a tool to assist with the estimation of quantities of medications to be included in the travelling pharmacy for future international multi-coded sports events.

\section{Acknowledgements}

The author would like to thank Dr Christa Janse van Rensburg, Dr Maki Ramagole and Dr Harald Adams for their tireless efforts in collection of the data used in this study.

\section{REFERENCES}

1. Alaranta A, Alaranta $\mathrm{H}$, Helenius I. Use of prescription drugs in athletes. Sports Med 2008; 38: 449-63.

2. Buettner CM. The team physician's bag. Clin Sports Med 1998; 17: 365-73.

3. Corrigan B, Kazlauskas R. Medication use in athletes selected for doping control at the Sydney Olympics (2000). Clin J Sport Med 2003; 13 : 33-40.

4. Derman WE. Medical care of the South African Olympic Team - the Sydney 2000 experience. South African Journal of Sports Medicine 2003; 15: $22-5$.

5. Derman WE. Profile of medical and injury consultations of Team South Africa during the XXVIIIth Olympiad, Athens 2004. South African Journal of Sports Medicine 2008; 20: 72-76.

6. Huang SH, Johnson K, Pipe AL. The use of dietary supplements and medications by Canadian athletes at the Atlanta and Sydney Olympic Games. Clin J Sport Med 2006; 16: 27-33.

7. Junge A, Langevoort G, Pipe A, et al. Injuries in team sport tournaments during the 2004 Olympic Games. Am J Sports Med 2006; 34: 565-76.

8. Katelaris $\mathrm{CH}$, Carrozzi FM, Burke TV. Allergic rhinoconjunctivitis in elite athletes: optimal management for quality of life and performance. Sports Med 2003; 33: 401-6.

9. Lippi G, Franchini M, Guidi GC, Kean WF. Non-steroidal anti-inflammatory drugs in athletes. Br J Sports Med 2006; 40: 661-2.

10. Milne CJ, Shaw MT. Travelling to China for the Beijing 2008 Olympic Games. Br J Sports Med 2008; 42: 321-6.

11. Shaw MT, Leggat PA, Borwein S. Travelling to china for the Beijing 2008 Olympic and Paralympic Games. Travel Med Infect Dis 2007; 5: 365-73.

12. Simon LM, Rubin AL. Traveling with the team Curr Sports Med Rep 2008; 7: 138-43.

13. Smith BJ, Collina SJ. Pain medications in the locker room: to dispense or not. Curr Sports Med Rep 2007; 6: 367-70.

14. Tscholl PM, Junge A, Dvorak J. The use of medication and nutritional supplements during FIFA World CupsTM 2002 and 2006. Br J Sports Med 2008; 42: 725-730.

\section{SPORTS PHYSICIAN - JOHANNESBURG}

An associate to join an established practice working out of 2 multidisciplinary sports clinics in Johannesburg is sought.

The suitable candidate must:

- be registered with the HPCSA

- have postgraduate sports medicine qualifications

- preferably have some experience working with athletes and sports teams

Interested candidates should e-mail their CVs to Sandy at jpat@mweb.co.za 